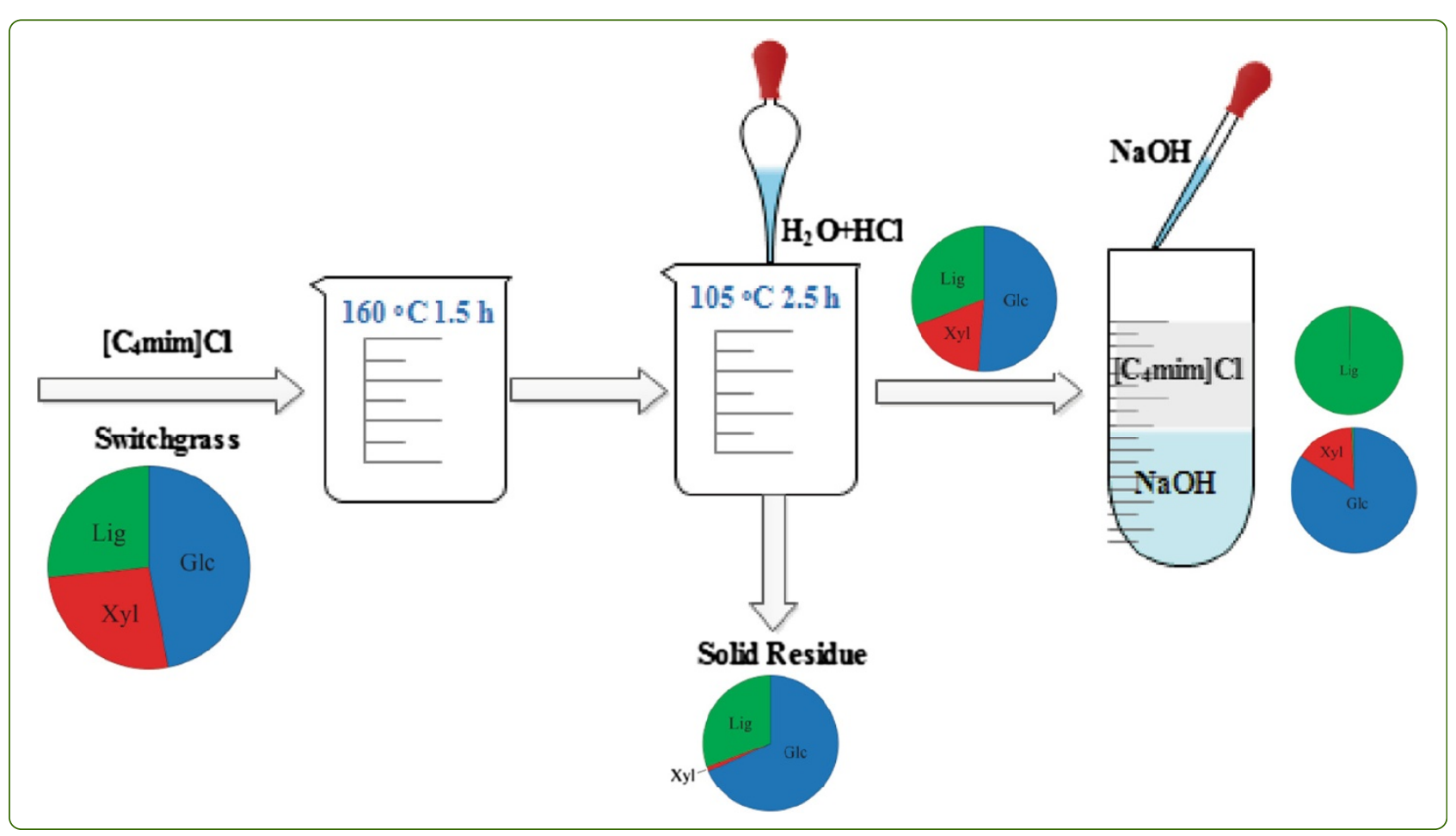

\title{
Production and extraction of sugars from switchgrass hydrolyzed in ionic liquids
}

Sun et al. 


\title{
Production and extraction of sugars from switchgrass hydrolyzed in ionic liquids
}

\author{
Ning Sun ${ }^{1}$, Hanbin Liu ${ }^{1,2}$, Noppadon Sathitsuksanoh ${ }^{1}$, Vitalie Stavila², Manali Sawant ${ }^{1}$, Anaise Bonito ${ }^{1}$, Kim Tran ${ }^{1,2}$, \\ Anthe George ${ }^{1,3}$, Kenneth L Sale ${ }^{1,2}$, Seema Singh ${ }^{1,2}$, Blake A Simmons ${ }^{1,2^{*}}$ and Bradley M Holmes ${ }^{1,2}$
}

\begin{abstract}
Background: The use of lonic liquids (ILS) as biomass solvents is considered to be an attractive alternative for the pretreatment of lignocellulosic biomass. Acid catalysts have been used previously to hydrolyze polysaccharides into fermentable sugars during IL pretreatment. This could potentially provide a means of liberating fermentable sugars from biomass without the use of costly enzymes. However, the separation of the sugars from the aqueous $\mathrm{IL}$ and recovery of $\mathrm{IL}$ is challenging and imperative to make this process viable.
\end{abstract}

Results: Aqueous alkaline solutions are used to induce the formation of a biphasic system to recover sugars produced from the acid catalyzed hydrolysis of switchgrass in imidazolium-based ILs. The amount of sugar produced from this process was proportional to the extent of biomass solubilized. Pretreatment at high temperatures (e.g., $160^{\circ} \mathrm{C}, 1.5 \mathrm{~h}$ ) was more effective in producing glucose. Sugar extraction into the alkali phase was dependent on both the amount of sugar produced by acidolysis and the alkali concentration in the aqueous extractant phase. Maximum yields of $53 \%$ glucose and $88 \%$ xylose are recovered in the alkali phase, based on the amounts present in the initial biomass. The partition coefficients of glucose and xylose between the IL and alkali phases can be accurately predicted using molecular dynamics simulations.

Conclusions: This biphasic system may enable the facile recycling of $\mathrm{IL}$ and rapid recovery of the sugars, and provides an alternative route to the production of monomeric sugars from biomass that eliminates the need for enzymatic saccharification and also reduces the amount of water required.

Keywords: Sugar extraction, Ionic liquids, Acidolysis, Aqueous biphasic system

\section{Background}

Lignocellulosic biomass is a renewable resource that may be converted to fuels and/or chemicals $[1,2]$. Recent research and development efforts have examined a two step bioconversion process that involves: 1) liberation of fermentable sugars from lignocellulose and, 2) conversion of sugars into fuels and/or chemicals by fermentation $[3,4]$. The potential of lignocellulosic biomass to serve as a renewable feedstock has not been realized, primarily due to the historical shift towards petroleum-based feedstocks

\footnotetext{
* Correspondence: basimmons@lbl.gov

${ }^{1}$ Deconstruction Division, Joint BioEnergy Institute, Lawrence Berkeley

National Laboratory, Berkeley, CA, USA

${ }^{2}$ Biological and Materials Sciences Center, Sandia National Laboratories, Livermore, CA, USA

Full list of author information is available at the end of the article
}

in the 1920s and the difficulty in depolymerization of lignocellulose into its component monomeric sugars [5].

The use of ionic liquids (ILs) as biomass solvents is an attractive alternative for the pretreatment of lignocellulosic biomass [6]. It has been shown that pretreatment with imidazolium-based ILs containing anions such as chloride [7], acetate [8] and alkyl phosphate [9], can greatly accelerate the subsequent enzymatic hydrolysis of biomass. Current approaches that use neat IL as the pretreatment solvent and water as antisolvent to precipitate carbohydrate-rich material require significant amounts of water to extract residual IL from the precipitated cellulose and undissolved biomass, and also require an effective means to recover and recycle the IL $[8,10]$. These requirements pose significant economic and sustainability

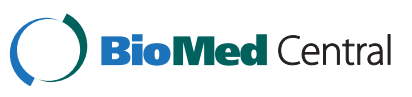


challenges to the deployment of the IL pretreatment technology [11].

Another approach to sugar production using ILs is to use acid catalysts to produce sugars and other compounds in situ through the hydrolysis of polysaccharides dissolved in imidazolium chloride [12-15]. Li et al. reported biomass hydrolysis in ILs with different mineral acids as catalysts and achieved a maximum $81 \%$ liberation of the total reducing sugars initially present in the biomass with 1-n-butyl-3-methylimidazolium chloride $\left(\left[\mathrm{C}_{4} \mathrm{mim}\right] \mathrm{Cl}\right)$ and hydrochloric acid [12]. The use of Brønsted acid ILs, which act as both the solvent and catalyst, to dissolve and hydrolyze cellulose has also been reported [16]. This could potentially provide a means of liberating fermentable sugars from biomass without employing enzymatic saccharification $[11,17]$. Separation of the sugars from the aqueous IL and recovery of the IL after acid hydrolysis are challenging and must be addressed in order to make this process economically viable.

Rogers et al. reported that certain hydrophilic ILs could form an aqueous biphasic system (ABS) in the presence of concentrated kosmotropic salts [18]. Subsequently, significant progress has been made that demonstrates the efficacy of this approach for separation of biomolecules, small organic molecules, biochemicals, and radiological isotopes [19-23]. It has been reported that an ABS can be formed with addition of an appropriate amount of $\mathrm{K}_{3} \mathrm{PO}_{4}, \mathrm{~K}_{2} \mathrm{HPO}_{4}, \mathrm{~K}_{2} \mathrm{CO}_{3}, \mathrm{KOH}, \mathrm{NaOH}$, or $\mathrm{Na}_{2} \mathrm{HPO}_{4}$ to an aqueous solution containing $\left[\mathrm{C}_{4} \mathrm{mim}\right]$ $\mathrm{Cl}[19,24]$. When added to certain aqueous IL solutions, kosmotropic anions stabilize water-water interactions, resulting in more energy being required for cavity formation around the bulky organic $\left[\mathrm{C}_{4} \mathrm{mim}\right]^{+}$cation. At a certain concentration of kosmotropic salts, an aqueous phase containing chaotropic IL can phase separate with the salt phase [23]. We describe a process that uses the phase separation behavior of imidazolium ILs/alkali/ water solutions in tandem with acid catalyzed hydrolysis to extract the sugars liberated from biomass from the aqueous IL solutions. This approach offers the potential of reducing costs of sugar production from lignocellulose by eliminating the need for enzymes and decreasing the water consumption requirements of more traditional IL pretreatment approaches.

\section{Results and discussion}

\section{Alkali extraction using sugar standards}

As shown in Figure 1, clear phase separation was obtained with addition of $2 \mathrm{~mL}$ of $15 \% \mathrm{NaOH}$ to $2 \mathrm{~g} \mathrm{IL}\left(\left[\mathrm{C}_{2} \mathrm{mim}\right] \mathrm{Cl}\right.$ or $\left[\mathrm{C}_{4} \mathrm{mim}\right] \mathrm{Cl}$ ). In the absence of glucose (or switchgrass), $10 \mathrm{wt} \% \mathrm{NaOH}$ phase separated with both $\left[\mathrm{C}_{2} \mathrm{mim}\right] \mathrm{Cl}$ or $\left[\mathrm{C}_{4} \mathrm{mim}\right] \mathrm{Cl}$. However, upon addition of switchgrass, no clear phase separation was observed with a final $\mathrm{NaOH}$ concentration of $10 \mathrm{wt} \%$. Therefore, $15 \mathrm{wt} \% \mathrm{NaOH}$ was used for processing switchgrass.

In order to determine the partition coefficients of sugars in water-IL solutions, mixtures of glucose $(0.033 \mathrm{~g})$ and xylose $(0.021 \mathrm{~g})$ were added to $\left[\mathrm{C}_{2} \mathrm{mim}\right] \mathrm{Cl}$ or $\left[\mathrm{C}_{4} \mathrm{mim}\right] \mathrm{Cl}$ aqueous solutions (ca $43 \% \mathrm{H}_{2} \mathrm{O}$, sugar concentrations are equivalent to $5 \mathrm{wt} \%$ switchgrass loading). To mimic acid hydrolysis conditions, $70 \mathrm{uL}$ of $4 \mathrm{M} \mathrm{HCl}$ was added to the mixture. After dissolution, a calculated amount of concentrated $\mathrm{NaOH}$ (50 wt \%) was added. The final concentration of $\mathrm{NaOH}$ in the system was either $15 \mathrm{wt} \%$ or $20 \mathrm{wt} \%$, and the sugar analysis results are plotted in Figure 2. The reported results (Extraction\%) are the percentage of the sugars in $\mathrm{NaOH}$ phase to the sugars in IL aqueous solution before phase separation calculated using Eq. 1:

$$
\text { Extraction } \%=\frac{C_{\text {low }} \times V_{\text {low }}}{C_{\text {sup }} \times V_{\text {sup }}} \times 100 \%
$$

where $C_{\text {low }}$ is the sugar concentration of the bottom (alkaline rich) phase, $V_{\text {low }}$ is the volume of the bottom phase, $C_{\text {sup }}$ is the sugar concentration of the supernatant before the addition of $\mathrm{NaOH}$, and $V_{\text {sup }}$ is the volume of the supernatant used for phase separation $(1 \mathrm{~mL})$.

Sugar concentrations before addition of $\mathrm{NaOH}$ correspond to $90-100 \%$ of the sugars added to the aqueous $\left[\mathrm{C}_{2} \mathrm{mim}\right] \mathrm{Cl}$ or $\left[\mathrm{C}_{4} \mathrm{mim}\right] \mathrm{Cl}$ solution, indicating minimal degradation of sugars under the conditions used for acidolysis. It was observed that more glucose is extracted to the bottom phase in comparison to xylose. For the upper IL rich phase, less than $1 \%$ glucose or xylose can be detected. The chromatograms of the upper and lower phases are shown in Additional file 1: Figure S1. It should be noted that due to the significantly different sugar concentrations present, the lower phase aliquot was diluted 3000x in order to be quantified by High Performance Anion Exchange Chromatography (HPAEC); however, the upper phase was only diluted $5 \times$. The system using $\left[\mathrm{C}_{4} \mathrm{mim}\right] \mathrm{Cl}$ was found to be more efficient, with better extractions for both glucose and xylose $\left(\left[\mathrm{C}_{4} \mathrm{mim}\right] \mathrm{Cl}\right.$ with $15 \% \mathrm{NaOH}$ : 96.5\% for glucose, $73.9 \%$ for xylose vs. $\left[C_{2} \operatorname{mim}\right] \mathrm{Cl}$ with 15\% NaOH: $90.1 \%$ for glucose, $59.2 \%$ for xylose). With higher concentrations of $\mathrm{NaOH}$, the amount of glucose partitioned to the lower phase is slightly higher $\left(\left[\mathrm{C}_{4} \mathrm{mim}\right]\right.$ Cl: $96.5 \%$ with $15 \%$ vs. $98.3 \%$ with $20 \%$; $\left[C_{2} \operatorname{mim}\right] \mathrm{Cl}$ : $90.1 \%$ with $15 \%$ vs. $92.0 \%$ with $20 \%$ ), while the amount of xylose in the bottom phase decreased $\left(\left[\mathrm{C}_{4} \mathrm{mim}\right] \mathrm{Cl}: 73.9 \%\right.$ with $15 \%$ vs. $60.9 \%$ with $20 \%$; $\left[C_{2} \mathrm{mim}\right] \mathrm{Cl}: 59.2 \%$ with $15 \%$ vs. $56.7 \%$ with $20 \%$ ). We hypothesized that this was due to the degradation of the xylose in strongly basic conditions. Based on the results obtained with sugar standards, $\left[\mathrm{C}_{4} \mathrm{mim}\right] \mathrm{Cl} /$ $15 \% \mathrm{NaOH}$ system was selected as the system for subsequent experiments with switchgrass.

Partitioning of glucose into the alkaline phase is driven by favorable interactions with the $\mathrm{NaOH}$ /water system as 


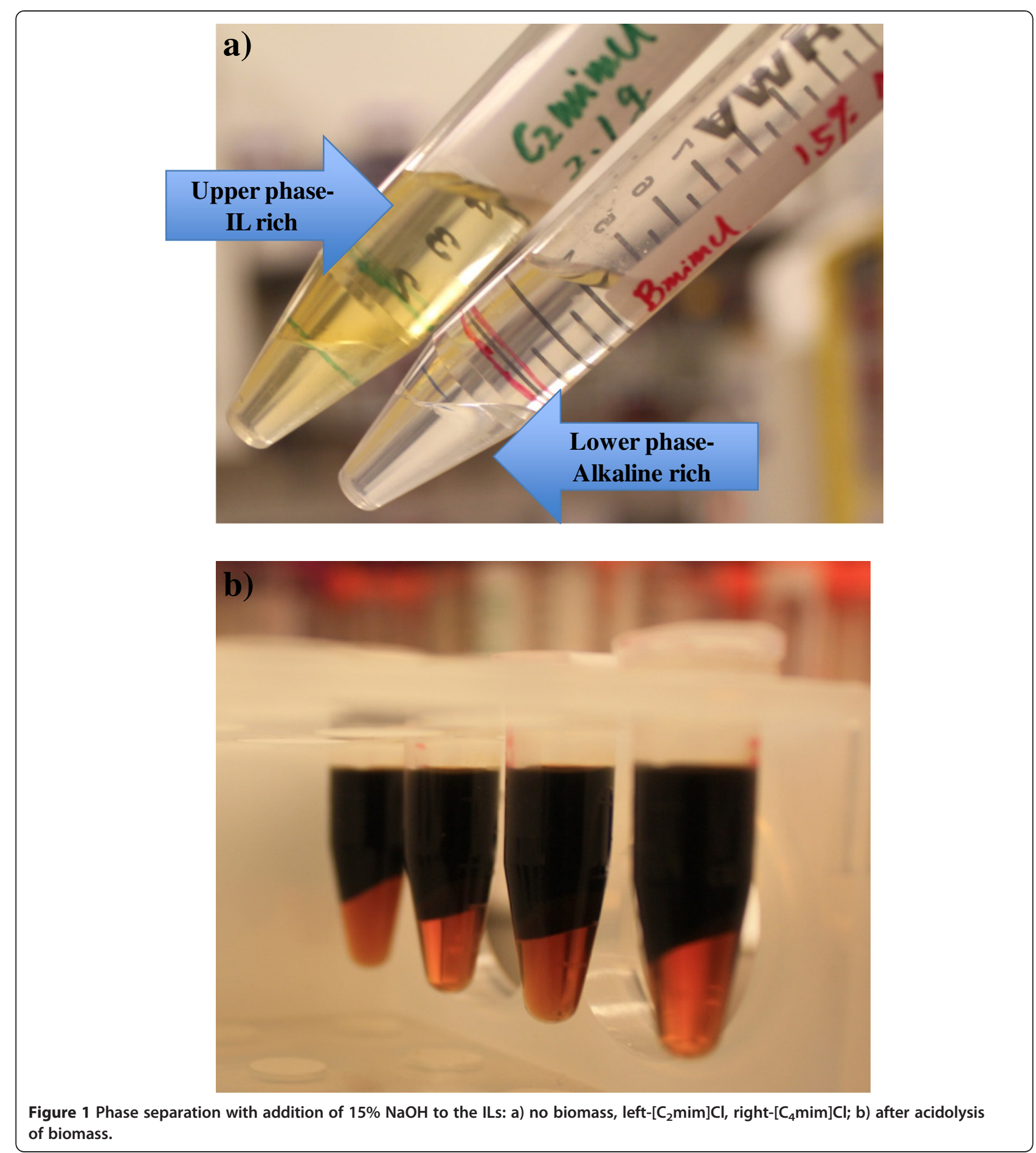

compared to the IL/water system. To evaluate the ability to accurately predict this partitioning based on the energetics of the interactions glucose has with the two solution environments, $10 \mathrm{~ns}$ molecular dynamics (MD) simulations were run from which the partition coefficient for glucose in each of the two phases was calculated according to Eqs. 2 and 3 using the last 8 ns of the simulation (Table 1).
The partition coefficients are calculated from the differences in interaction energies of glucose with different solvent systems:

$$
\log P=\frac{\Delta \Delta G}{2.3 \times R \times T}
$$




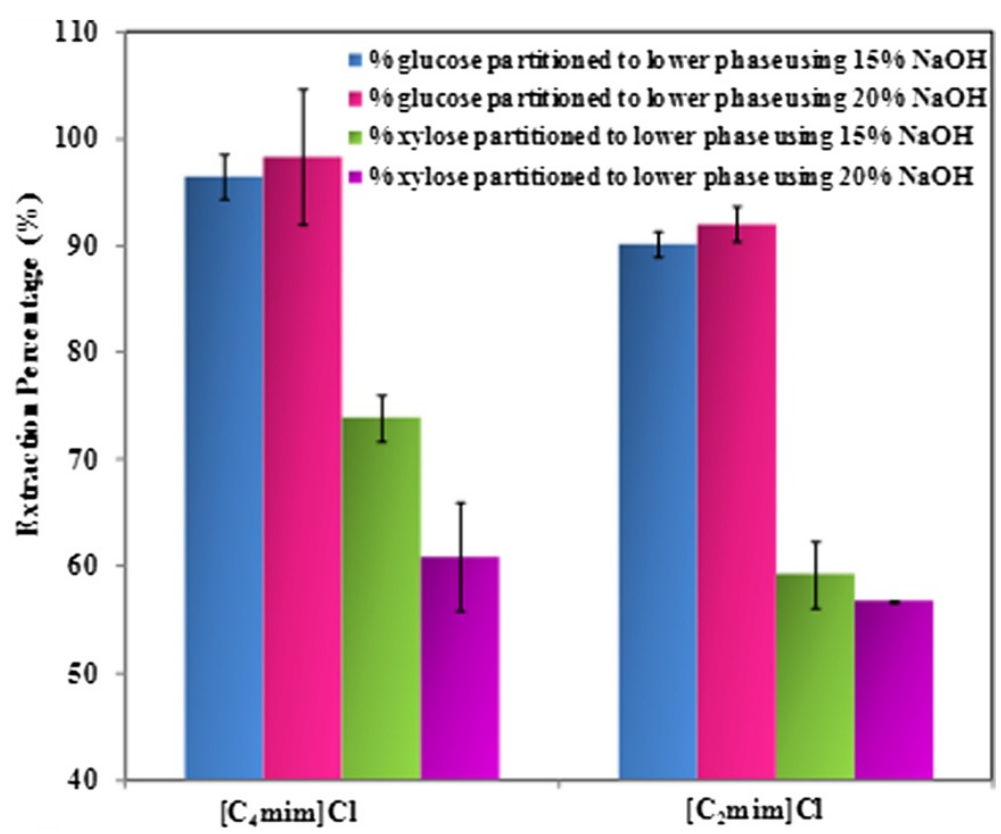

Figure 2 Percentage of glucose and xylose partitioned to the lower alkaline rich phase using two different $\mathrm{NaOH}$ concentrations.

where the difference in interaction energy is calculated as:

$$
\begin{aligned}
\Delta \Delta G \approx \Delta \Delta E & =\left(E_{\text {sugar }, \text { NaOH phase }}-E_{\text {sugar }}-E_{\text {NaOH phase }}\right) \\
& -\left(E_{\text {sugar }, \text { LL phase }}-E_{\text {sugar }}-E_{\text {IL phase }}\right) \\
& =\left(E_{\text {sugar }, \text { NaOH phase }}-E_{\text {NaOH phase }}\right) \\
& -\left(E_{\text {sugar }, I L \text { phase }}-E_{\text {IL phase }}\right)
\end{aligned}
$$

The calculated interaction energy of glucose with the $\mathrm{NaOH} /$ water systems is more preferred (lower interaction energy) than the interaction energy of glucose in the IL/ water system, indicating that glucose tends to partition into the alkaline phase. The more preferred interactions between glucose and $\mathrm{NaOH} /$ water solutions also indicates that the hydroxyl group forms stronger hydrogen bonds with the anionic $\mathrm{OH}^{-}$group due to the stronger charge distribution around the $\mathrm{OH}^{-}$anions. The calculated partition coefficient is 2.91 and agrees well with the experimental

Table 1 The total potential energies of the simulated systems

\begin{tabular}{lcc}
\hline & {$\left[\mathbf{C}_{\mathbf{2}} \mathbf{m i m}\right] \mathbf{C l}(\mathbf{k c a l} / \mathbf{m o l})$} & $\mathbf{N a O H}(\mathbf{k c a l} / \mathbf{m o l})$ \\
\hline Sugar + system & -3998.02 & -22477.84 \\
Solvent only & -4500.37 & -22948.28 \\
$\Delta \mathrm{E}$ & 502.36 & 470.44 \\
$\Delta \Delta \mathrm{E}$ (per glucose) & & -3.99 \\
\hline
\end{tabular}

result of 3.18. These results suggest that MD simulations can be used to understand the partitioning of monomeric sugars into various $\mathrm{IL} /$ water and $\mathrm{NaOH} /$ water systems and to predict partition coefficients of sugars into these systems to assist in the choice of the IL.

\section{Biomass pretreatment and acidolysis}

It was previously reported that rapid "flash" heating (higher temperature and shorter time) using certain ILs to pretreat biomass is more efficient with regards to the carbohydrate yield and removal of lignin [25]. Previous results from our group have typically used temperatures between $120-160^{\circ} \mathrm{C}$ and time intervals of $1-3 \mathrm{~h}$ [26]. In order to define the best set of conditions for pretreatment and acidolysis, switchgrass was processed using different pretreatment combinations of temperature, time and water addition protocols, and the results are compared in Table 2 and Figure 3. After pretreatment at $160^{\circ} \mathrm{C}$ for $1.5 \mathrm{~h}$ and $5 \%$ solids loading, particles were not observed and the mixture was a homogenous dark solution. Thus, the pretreatment time under $160^{\circ} \mathrm{C}$ was not carried out longer than $1.5 \mathrm{~h}$. The sugar yields obtained after pretreatment and hydrolysis were calculated using Eq. 4:

$$
\text { Yield } \%=\frac{C_{\text {sup }} \times T V_{\text {sup }}}{W_{\text {sg }} \times C_{\text {sug }} \times f} \times 100 \%
$$

where, $T V_{\text {sup }}$ is the total volume of the supernatant, $W_{\text {sg }}$ is the weight of the switchgrass pretreated by $\mathrm{IL}, C_{\text {sug }}$ is the percentage of glucan/xylan contained in the switchgrass, and $f$ is the factor to convert glucan/xylan to glucose/xylose 
Table 2 Glucose and xylose yields after acidolysis of biomass in $\left[C_{4} \mathrm{mim}\right] \mathrm{Cl}$ using different pretreatment conditions and water addition methods ${ }^{a}$

\begin{tabular}{llllll}
\hline Run no. & Pretreatment conditions & $\mathbf{H}_{\mathbf{2}} \mathrm{O}$ addition method & Solid residue (wt\%) & Glucose yield (\%) & Xylose yield (\%) \\
\hline 1 & $105^{\circ} \mathrm{C} 6 \mathrm{~h}$ & Aliquot & 34.9 & $20.7 \pm 0.4$ & $99.8 \pm 2.6$ \\
$2^{\mathrm{b}}$ & $105^{\circ} \mathrm{C} 6 \mathrm{~h}$ & Aliquot & 34.8 & $24.2 \pm 0.3$ & $98.6 \pm 1.8$ \\
$3^{\mathrm{c}}$ & $105^{\circ} \mathrm{C} 6 \mathrm{~h}$ & Aliquot & 34.8 & $27.4 \pm 0.7$ & $95.1 \pm 2.0$ \\
4 & $160^{\circ} \mathrm{C} 1 \mathrm{~h}$ & Aliquot & 13.7 & $37.1 \pm 1.2$ & $83.4 \pm 3.8$ \\
5 & $160^{\circ} \mathrm{C} 1.5 \mathrm{~h}$ & Aliquot & 6.7 & $69.4 \pm 2.5$ & $81.9 \pm 2.8$ \\
6 & $160^{\circ} \mathrm{C} 1.5 \mathrm{~h}$ & Pumped @ 10 min & 13.8 & $38.6 \pm 2.7$ & $92.6 \pm 5.5$ \\
7 & $160^{\circ} \mathrm{C} 1.5 \mathrm{~h}$ & Pumped @ 15 min & 10.2 & $83.3 \pm 1.9$ & $52.1 \pm 1.2$ \\
\hline
\end{tabular}

${ }^{\mathrm{a}}$ For all runs, $0.5 \mathrm{~g}$ biomass was mixed with $10 \mathrm{~g}\left[\mathrm{C}_{4} \mathrm{mim}\right] \mathrm{Cl} ;{ }^{\mathrm{b}} 7.5 \mathrm{~mL}$ water was added at the end of the acidolysis; ${ }^{\mathrm{c}} 15 \mathrm{~mL}$ water was added at the end of the acidolysis.

(1.11 for glucan and 1.136 for xylan). The results show that the final dilution is not necessary since the glucose yield is improved by $35 \%$ with $37 \%$ more water in the system and xylose yields are similar. With increased temperature and decreased pretreatment time the glucose yield increased from $20.7 \%$ to $69.4 \%$, while xylose recovery decreased from $99.8 \%$ to $81.9 \%$, possibly due to enhanced xylose degradation at higher temperatures. Compared to the reported data, these glucose yields are lower under the $105^{\circ} \mathrm{C} / 6 \mathrm{~h}$ pretreatment condition [27]. We attribute these differences to the different types of biomass used (corn stover vs. switchgrass), types of IL $\left(\left[\mathrm{C}_{2} \mathrm{mim}\right] \mathrm{Cl}\right.$ vs. $\left.\left.\mathrm{C}_{4} \mathrm{mim}\right] \mathrm{Cl}\right)$, and the scale of the biomass loading $(26.7 \mathrm{mg}$ g corn stover + $502 \mathrm{mg}$ IL vs. $0.5 \mathrm{~g} \mathrm{SG}+10 \mathrm{~g}$ IL), all of which are essential factors that affect the final yields.

In previous reports [27], water was added at defined time intervals ( $0 \mathrm{~min}, 10 \mathrm{~min}, 20 \mathrm{~min}, 30 \mathrm{~min}$ and $60 \mathrm{~min}$ ) during acidolysis to achieve higher sugar yields. As this may not be a practical approach to water addition, we evaluated the impact of pumping water into the system using a syringe pump, and the results are compared from runs 5 to 7 Table 2. Runs 6 and 7 indicate that the time interval when the water was pumped into the system has a significant impact on the observed sugar yield. For example, in run 6, water was pumped in $10 \mathrm{~min}$ after the initial addition of water and acid; the glucose yield was observed to decrease significantly (Run 5 69.4\% vs. Run 6 $38.6 \%$ ) although they were pretreated under the same conditions: $160^{\circ} \mathrm{C}$ for $1.5 \mathrm{~h}$. When the reaction interval was changed to $15 \mathrm{~min}$ with $20 \%$ water addition performed at $10 \mathrm{~min}$, the glucose yield improved from $69.4 \%$ to $83.3 \%$. We hypothesize that this result can be attributed to the kinetics of the glucose hydrolysis based on observations made in previous reports [27], and the optimized water addition are plotted in Additional file 1: Figure S2. Figure 3 shows clearly that the maximum glucose yields occur at the expense of reduced xylose yields, which is expected, as xylan is easier to hydrolyze compared to glucan. At more severe process conditions, more glucan can be broken down but this also results in spontaneous $\mathrm{xy}$ lose degradation.

As concentrated sugar hydrolysates are favored for downstream fermentation, we explored the impact of higher switchgrass solid loading levels, and the results are shown in Table 3. Although more solid residue (absolute mass) remains after the pretreatment-acidolysis process and the

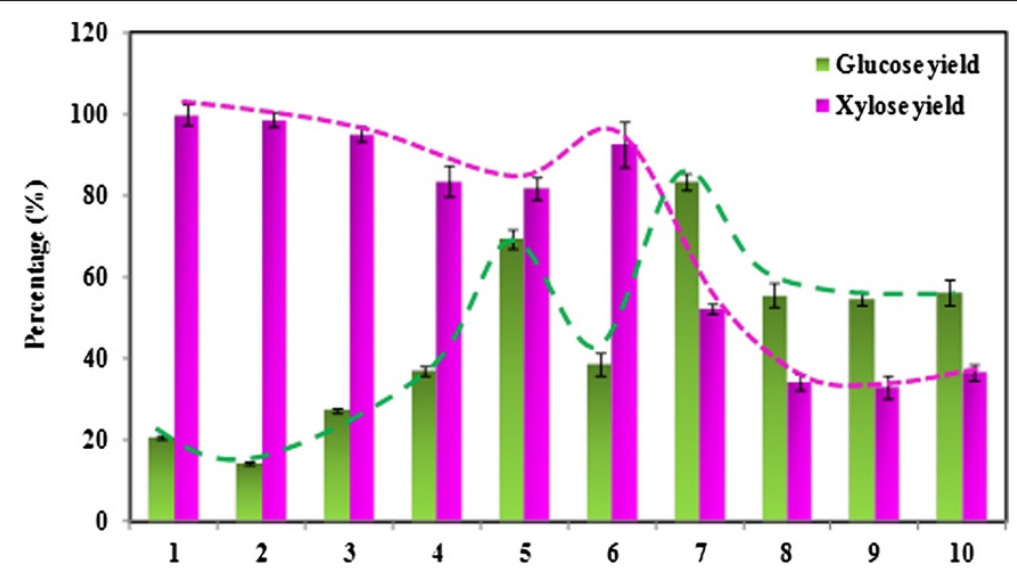

Figure $3 \mathrm{Glucose}$ and xylose yield after acidolysis of switchgrass in $\left[\mathbf{C}_{4} \mathrm{mim}\right] \mathrm{Cl}$. The number of the $x$-axis label corresponds to the run numbers in Tables 2 and 3. 
Table 3 Glucose and xylose yields after acidolysis of biomass in $\left[\mathrm{C}_{4} \mathrm{mim}\right] \mathrm{Cl}$ using different solids loadings ${ }^{a}$

\begin{tabular}{ccccccc}
\hline $\begin{array}{c}\text { Run } \\
\text { No. }\end{array}$ & $\begin{array}{c}\text { Solid } \\
\text { loading } \\
\text { (w/w) }\end{array}$ & $\begin{array}{c}\text { Solid } \\
\text { residue } \\
\text { (wt\%) }\end{array}$ & $\begin{array}{c}\text { Glucose } \\
\text { yield (\%) }\end{array}$ & $\begin{array}{c}\text { Xylose } \\
\text { yield (\%) }\end{array}$ & $\begin{array}{c}\text { Final } \\
{[\mathbf{G l c}](\mathbf{g} / \mathbf{L})}\end{array}$ & $\begin{array}{c}\text { Final } \\
[\mathbf{X y l}] \mathbf{( g / L})\end{array}$ \\
\hline 7 & 5 & 10.2 & $83.3 \pm 1.9$ & $52.1 \pm 1.2$ & $8.0 \pm 0.2$ & $3.4 \pm 0.1$ \\
8 & 7.5 & 9.7 & $55.5 \pm 3.0$ & $34.1 \pm 2.0$ & $8.3 \pm 0.4$ & $3.5 \pm 0.2$ \\
9 & 10 & 9.4 & $54.4 \pm 1.6$ & $32.9 \pm 2.8$ & $10.2 \pm 0.3$ & $6.7 \pm 0.4$ \\
10 & 15 & 8.0 & $56.2 \pm 3.1$ & $36.7 \pm 1.9$ & $15.5 \pm 0.8$ & $6.9 \pm 0.4$ \\
\hline
\end{tabular}

a water was pumped into the system $15 \mathrm{~min}$ after pretreatment.

${ }^{b}$ solid loading is the ratio of the mass of SG to mass of IL.

glucose/xylose yields decrease $(83.3 \%$ vs. $54.4 \%$ for glucose and $52.1 \%$ vs. $32.9 \%$ for xylose), the final glucose/xylose concentration in the system increased to $15.5 \mathrm{~g} / \mathrm{L}$ for glucose and $6.9 \mathrm{~g} / \mathrm{L}$ for xylose. This may indicate that in order to obtain high sugar concentrations at high yields, a multi-cycle pretreatment process using this approach should be considered.

\section{Sugar extraction after acidolysis of biomass}

After the acidolysis step, the supernatant was separated from the solid biomass residue by centrifugation. $1 \mathrm{~mL}$ supernatant was loaded in eppendorf tubes and the calculated amount of concentrated $\mathrm{NaOH}$ was added into the tubes. After vigorous mixing the solution was centrifuged and clear evidence of phase separation was observed (Figure 1b). Sugar extraction was calculated based on the percentage of sugars in the alkaline phase to the sugars present in the supernatant before phase separation (Eq. 1), and the results are presented in Figure 4 and Table 4. Overall, more glucose partitioned to the alkaline phase compared to xylose as observed by comparing the first two columns in Figure 4 (Runs 1-7). With higher solid loadings, more xylose partitioned to the lower phase indicating the effect of biomass components such as lignin or carbohydrate oligomers on sugar partitioning. With higher glucose yields (e.g. Run 7: 83.3\% vs. Run 1: 20.7\%) from the acid hydrolysis, less sugar partitioned to the lower phase (Run 7: 64.1\% vs. Run 1: 98.5\%). After extraction, less than $2 \%$ of the sugars remain in the $\left[\mathrm{C}_{4} \mathrm{mim}\right] \mathrm{Cl}$ phase. The final sugar yields in the last two columns of Table $4\left(\mathrm{GY}_{\mathrm{NaOH}}, \mathrm{XY}_{\mathrm{NaOH}}\right)$ represent how much sugar was recovered in the alkaline phase, calculated using Eq. 5:

$$
G Y_{\mathrm{NaOH}} \text { or } X Y_{\mathrm{NaOH}}=Y_{\text {sug }} \times E_{\text {sug }} \times 100 \%
$$

where $Y_{\text {sug }}$ is the sugar yield calculated according to Eq. 4 and $E_{\text {sug }}$ is the extraction percentage calculated based on Eq. 1. Overall, up to $54 \%$ of the glucose or $88 \%$ of xylose in original switchgrass can be released and then extracted to the alkaline phase (different pretreatment conditions are required depending on whether $\mathrm{C} 5$ or $\mathrm{C} 6$ is the focus). With more glucose recovered, less xylose can be obtained and a limited amount $(<0.06 \mathrm{~g} / \mathrm{L})$ of sugars were detected in the $\left[\mathrm{C}_{4} \mathrm{mim}\right] \mathrm{Cl}$ phase, ca. $50 \%$ of the sugars were lost after the process under the optimized conditions (Run 5 with final sugar yields in alkaline phase: $54.23 \%$ for glucose; $47.01 \%$ for xylose). It was reported that $82 \%$ glucose yield and less than $18.5 \%$ xylose was obtained in the hydrolysate after pretreatment of switchgrass (3\% w/w biomass loading) in 1-ethyl-3-methylimidazolium acetate $\left(\left[\mathrm{C}_{2} \mathrm{mim}\right] \mathrm{OAc}\right)$ at $160^{\circ} \mathrm{C}$ for $3 \mathrm{~h}$ followed by $72 \mathrm{~h}$ enzymatic saccharification [28]. Although the glucose yield from the acidolysis-extraction process is lower than that reported using the more conventional IL pretreatment approach, the significantly higher xylose recovery, elimination of the extensive washing steps normally required to remove IL residue in pretreated biomass, and elimination of the costly hydrolytic enzymes suggest that this process may offer compelling economic advantages. The partition coefficients for glucose fall into the same range as those obtained with the sugar standards (2.96-3.39 vs. 2.91). The partition coefficients for xylose are less than those for glucose (2.58-3.28). At higher biomass loadings

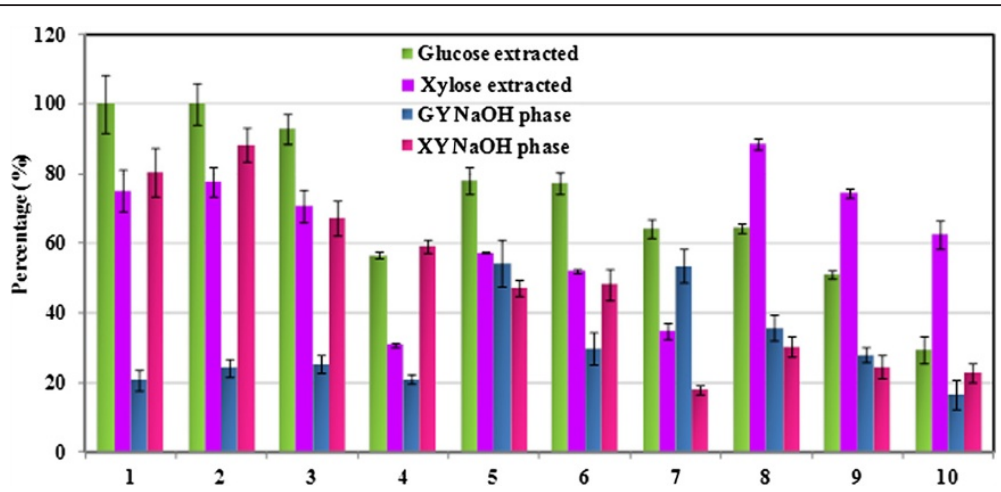

Figure 4 Percentage of glucose and xylose partitioned to the alkaline phase (first two columns) and final sugar yields (GY: glucose yield, XY: xylose yield) in the alkali phase (last two columns, calculated according to Eq. 5). The number of the x-axis label corresponds to the run numbers in Tables 2 and 3. 
Table 4 Partition of the sugars after phase separation

\begin{tabular}{ccccccccc}
\hline Run no. & {$[\mathbf{G l c}]_{\mathbf{L L}}(\mathbf{g} / \mathbf{L})^{\mathbf{a}}$} & {$[\mathbf{G l c}]_{\mathbf{N a O H}}(\mathbf{g} / \mathbf{L})$} & $\log P_{\mathbf{g l c}}$ & {$[\mathbf{X y l}]_{\mathbf{I L}}(\mathbf{g} / \mathbf{L})^{\mathbf{a}}$} & {$[\mathbf{X y l}]_{\mathrm{NaOH}}(\mathbf{g} / \mathbf{L})$} & $\log _{\mathbf{x y l}}$ & $\mathbf{G Y}_{\mathrm{NaOH}}(\%)^{\mathbf{b}}$ & $\mathbf{X Y}$ \\
\hline 1 & 0.004 & $8.55 \pm 0.65$ & 3.33 & $\mathrm{ND}$ & $18.58 \pm 1.50$ & - & 22.64 & 80.33 \\
2 & 0.002 & $2.31 \pm 0.13$ & 3.06 & $\mathrm{ND}$ & $7.47 \pm 0.41$ & - & 15.60 & 88.26 \\
3 & 0.001 & $2.46 \pm 0.11$ & 3.39 & 0.002 & $3.62 \pm 0.24$ & 3.26 & 25.26 \\
4 & 0.007 & $8.84 \pm 0.13$ & 3.10 & 0.003 & $5.71 \pm 0.10$ & 3.28 & 20.98 & 57.19 \\
5 & 0.016 & $17.84 \pm 0.27$ & 3.05 & 0.005 & $8.24 \pm 0.05$ & 3.22 & 54.23 & 47.05 \\
6 & 0.008 & $10.07 \pm 0.17$ & 3.10 & 0.005 & $8.10 \pm 0.17$ & 3.21 & 29.81 & 48.15 \\
7 & 0.018 & $24.73 \pm 1.39$ & 3.14 & 0.006 & $7.00 \pm 0.65$ & 3.07 & 53.42 & 18.07 \\
8 & 0.020 & $26.56 \pm 0.28$ & 3.12 & 0.040 & $15.20 \pm 0.49$ & 2.58 & 35.72 & 30.23 \\
9 & 0.023 & $28.06 \pm 0.26$ & 3.09 & 0.041 & $26.91 \pm 0.42$ & 2.82 & 27.82 & 24.46 \\
10 & 0.036 & $32.94 \pm 2.86$ & 2.96 & 0.057 & $30.86 \pm 3.19$ & 2.73 & 16.57 & 22.91
\end{tabular}

Note: $[\mathrm{Glc}]_{\mathrm{IL}}$ or $[\mathrm{Xyl}]_{\mathrm{IL}}$ is glucose or xylose concentration in the IL phase; $[\mathrm{Glc}]_{\mathrm{NaOH}}$ or $[\mathrm{Xyl}]_{\mathrm{NaOH}}$ is glucose or xylose concentration in NaOH phase; ND: not detected. a The standard deviation is within $20 \%$ of the measurement. The deviation is due to the low concentration of the sugars in IL phase and detection limit of the instrument. ${ }^{b} \mathrm{GY} \mathrm{NaOH}_{\text {is }}$ is the final glucose yield in $\mathrm{NaOH}$ phase (percentage of the glucose in original biomass); $\mathrm{XY}_{\mathrm{NaOH}}$ is the final $\mathrm{xylose}$ yield in $\mathrm{NaOH}$ phase (percentage of the xylose in original biomass).

(Runs 8-10), the partition coefficients for both glucose and xylose are observed to decrease, and the variation of $\log \mathrm{P}$ between runs indicates again that other biomass components present in the solution may interfere with partitioning.

Sugars can also be lost due to spontaneous degradation to other small molecules during acidolysis and/or sugar extraction. For example, glucose and xylose can be dehydrated to furans and other degradation products under acidic conditions [29]. In order to determine the extent to which this occurred during acidolysis, 5(hydroxymethyl)furfural (HMF) and furfural were quantified in the supernatant as well as the upper and lower phases, and the results are listed in Table 5. The results show that only up to $5 \%$ of the glucose (equivalent) was converted to HMF after acidolysis, but more xylose (5-11\%) was dehydrated to furfural. Neither furfural nor HMF can be detected by liquid chromatography in the two phases after the addition of concentrated $\mathrm{NaOH}$, but further work is needed to verify these results as it is expected that these degradation products would partition with the sugars.

The $\left[\mathrm{C}_{4} \mathrm{mim}\right] \mathrm{Cl}$ content was determined in the alkaline phase and the results are listed in Table 6. The percentage of the $\left[\mathrm{C}_{4} \mathrm{mim}\right] \mathrm{Cl}$ present in the lower phase was found to be dependent on the pretreatment conditions. At higher temperature and shorter pretreatment time (Runs 4-10), less than $1 \%$ of the $\left[\mathrm{C}_{4} \mathrm{mim}\right] \mathrm{Cl}$ in the supernatant is observed to partition to the alkaline phase. Comparatively, $5-9 \%$ of the $\left[\mathrm{C}_{4} \mathrm{mim}\right] \mathrm{Cl}$ partitioned to the lower phase for runs $1-3$ at lower temperature and longer pretreatment time. The highest $\left[\mathrm{C}_{4} \mathrm{mim}\right] \mathrm{Cl}$ content was found in the alkaline phase with $15 \mathrm{~mL}$ water dilution at the end of the acidolysis. NMR analysis (Additional file 1: Figure S3) shows that the $\left[\mathrm{C}_{4} \mathrm{mim}\right] \mathrm{Cl}$ present in the upper phase is the same as the signal obtained from the original
$\left[\mathrm{C}_{4} \mathrm{mim}\right] \mathrm{Cl}$, while no signal can be detected in the lower (alkaline) phase with NMR.

\section{Mass balance and characterization of the solid residue}

After the acidolysis process, a small quantity of solid was obtained. This solid residue is expected to be the most recalcitrant part of the plant cell wall, and different analytical techniques were used to characterize the material. $\mathrm{X}$-ray diffraction (XRD) was used to determine the proportions of crystalline (highly ordered) and disordered components (amorphous cellulose, hemicelluloses and lignin) present in biomass samples, and to monitor the structural changes upon $\left[\mathrm{C}_{4} \mathrm{mim}\right] \mathrm{Cl}$ treatment and acidolysis. Commercial Avicel was used as a cellulose standard to validate the results. In general, the solid residue recovered after pretreatment and acidolysis has a significant reduction in the degree of crystallinity present as compared to the untreated switchgrass (Figure 5). The XRD patterns are observed to be dependent on the pretreatment conditions. At the lower pretreatment temperature (Run $1, \mathrm{~T}=105^{\circ} \mathrm{C}$ ),

\section{Table 5 Quantification of the HMF and furfural in} the system

\begin{tabular}{lll}
\hline Run no. & \% Glu. to HMF & \% Xyl. to furfural \\
\hline 1 & $2.16 \pm 0.00$ & $6.07 \pm 0.01$ \\
2 & $1.79 \pm 0.01$ & $6.05 \pm 0.02$ \\
3 & $2.05 \pm 0.01$ & $5.63 \pm 0.02$ \\
4 & $2.95 \pm 0.01$ & $5.88 \pm 0.01$ \\
5 & $4.79 \pm 0.06$ & $8.52 \pm 0.02$ \\
6 & $3.25 \pm 0.03$ & $9.01 \pm 0.02$ \\
7 & $5.14 \pm 0.02$ & $10.93 \pm 0.00$ \\
8 & $3.66 \pm 0.02$ & $4.66 \pm 0.04$ \\
9 & $3.20 \pm 0.00$ & $6.23 \pm 0.01$ \\
10 & $4.53 \pm 0.00$ & $9.35 \pm 0.07$ \\
\hline
\end{tabular}


Table 6 Quantification of the IL in the lower alkaline rich phase

\begin{tabular}{llll}
\hline Run & Dilution $(\mathbf{m L})$ & $\begin{array}{l}{\left[\mathbf{C}_{4} \text { mim]Cl in }\right.} \\
\text { alkali phase }(\mathbf{m M})\end{array}$ & $\begin{array}{l}\% \text { of IL to the } \\
\text { alkaline phase }\end{array}$ \\
\hline 1 & 0 & 784.5 & 5.8 \\
2 & 1.5 & 302.6 & 5.9 \\
3 & 3 & 317.0 & 9.4 \\
4 & 0 & 75.2 & 0.6 \\
5 & 0 & 63.5 & 0.4 \\
6 & 0 & 70.6 & 0.5 \\
7 & 0 & 39.9 & 0.3 \\
8 & 0 & 97.2 & 0.6 \\
9 & 0 & 90.3 & 0.5 \\
10 & 0 & 86.1 & 0.4 \\
\hline
\end{tabular}

solid residue after pretreatment and acidolysis displays a crystal structure very similar to that of the original biomass (cellulose I). In addition to cellulose I peaks $\left(15-16^{\circ}\right.$ for 101 and $10 \overline{1}, 22^{\circ}$ for 002 ), a shoulder around $21.5^{\circ}$ is also observed, suggesting at least partial conversion to cellulose II. Overall, the calculated CrI shows a decrease from 0.38 to 0.29 with pretreatment at $105^{\circ} \mathrm{C}$ for $6 \mathrm{~h}$.

In contrast, the biomass pretreatment at higher temperature results in disappearance of the broad peak at ca. $15-16^{\circ}$, which represents a combination of the 101 and $10 \overline{1}$ planes of cellulose I. The material is highly amorphous with a minor crystalline component $(\mathrm{CrI}=0.08)$. The broad peak around $21.4^{\circ}$ may be assigned to the 002 cellulose II lattice plane. This indicates that the solvent IL has penetrated inside the solid part and disrupted the crystal structure of cellulose during the higher temperature pretreatment. This may explain why higher temperature/ shorter time pretreatment is more efficient in solubilizing the biomass, thus resulting in more sugar production. Another possible explanation for the observed structural change is that the relative ratio of the three major biomass components is altered as a result of the pretreatment.

Glucan, xylan and lignin (acid insoluble) contents of the solid residue were quantified and the results are listed in Additional file 1: Table S1. After the pretreatment and acidolysis process, the glucan contents in the solid residue are generally higher as compared to their relative abundance in the original biomass. Xylan contents are all under $5 \%$, indicating most of xylan has been solubilized/hydrolyzed. Lignin content in the solid residue is generally close to the original switchgrass for higher temperature pretreatment (Run 7-10). A mass balance for Run 7 is shown in Figure 6, and it should be noted that less xylose is observed in the $\mathrm{NaOH}$ phase, and that a significant amount of the lignin remains in the IL phase and would need to be removed in order to recycle the IL.

The solid residue was analyzed with 2D NMR to further define the solid residue and the spectra are shown

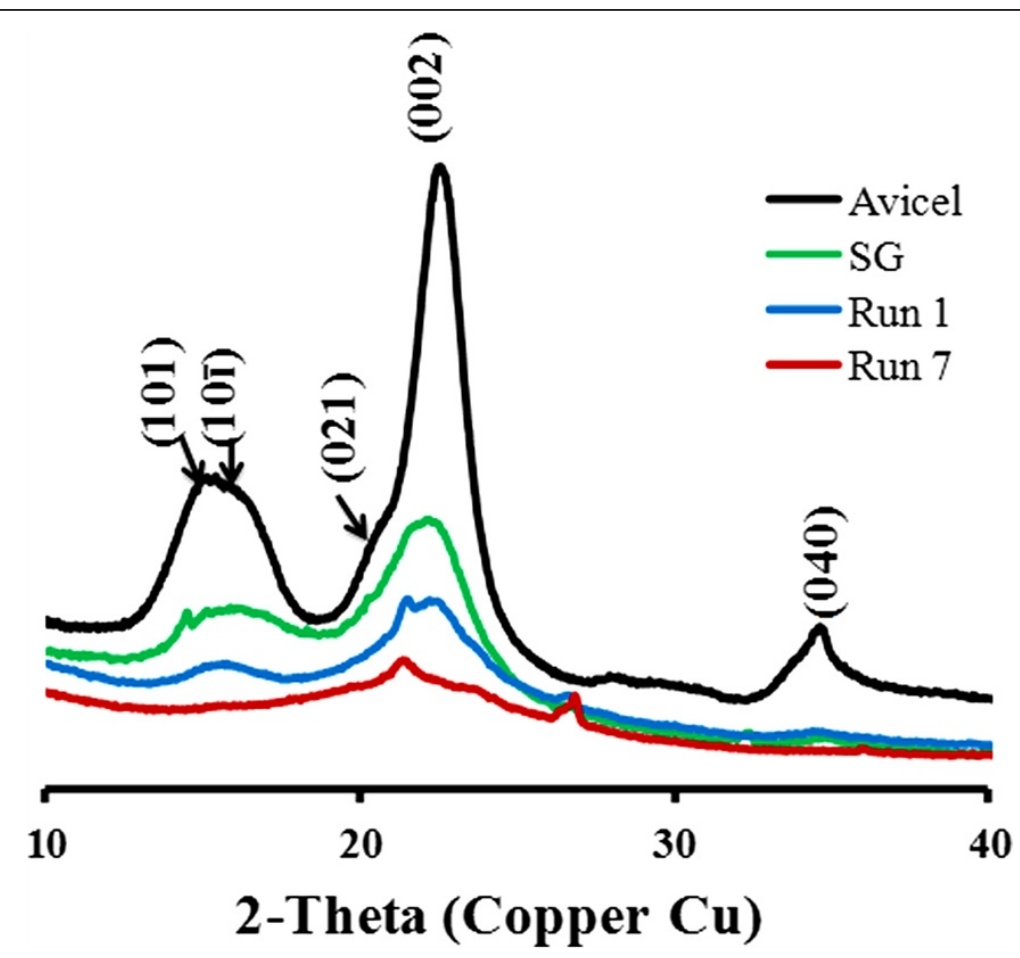

Figure 5 Diffractograms of the biomass before and after the process. Red, Avicel, Green, switchgrass, Blue: solid residue from run 1, Purple: solid residue from run 7. Crl of Avicel: 0.74, SG: 0.38, Run 1: 0.29, Run 5: 0.08. 


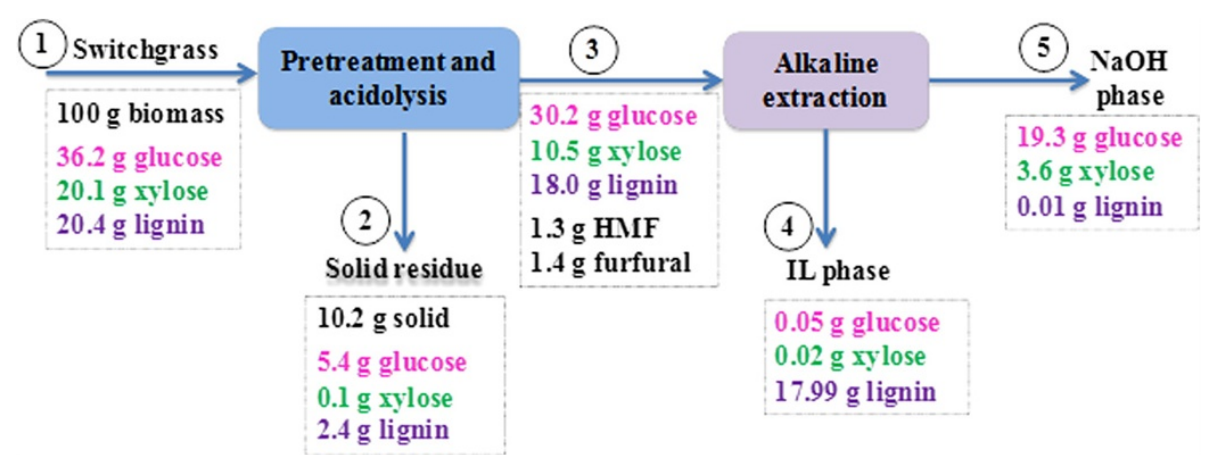

Figure 6 Representative mass balance of lignocellulose as defined by the process conditions used in Run 7. Lignin/sugars in the solid samples (stream 1 and 2) were quantified using the standard method [33]; lignin in $\mathrm{NaOH}$ phase (stream 5) was quantified gravimetrically by adjusting the $\mathrm{pH}$ of the solution to $\mathrm{pH}=2-3$ using $4 \mathrm{~N} \mathrm{HCl}$; lignin in stream 3 and 4 was calculated by subtraction; sugars in the liquid stream (3-5) were quantified using HPAEC.

in Figure 7. It has been shown that a mixture of perdeuterated DMSO/pyridine $(4: 1, \mathrm{v} / \mathrm{v})$ is a better solvent compared to DMSO-d6 only with regards to sample handling as well as the resolution and intensities of NMR spectra [30], and thus a mixture of perdeuterated DMSO/pyridine (4:1, v/v) was chosen as the solvent. The aromatic region (4.0-5.5/102-150 ppm) of the 2D HSQC spectra provides information on the p-hydroxyphenyl:guaiacyl:syringyl (H:G:S) distributions in the lignin. According to the spectra in Additional file 1: Figure S4, the switchgrass lignin is dominated by G lignin with less amount of $\mathrm{H}$ and $\mathrm{S}$ units which is consistent with previous results presented in the literature [31]. The correlation of S2/6 (6.78/104.02) and H2/6 (7.24/ $127.8 ; 7.27 / 128.93)$ are very weak can only be seen at a low contour level. The $\mathrm{C} / \mathrm{H}$ correlations from the $\mathrm{G}$ aromatic rings (G2, G5 and G6) are well resolved for both samples, except that G5 $(6.88 / 115.55)$ is overlapping with ferulate (FA) and $p$-coumarate $(p \mathrm{CA}): \mathrm{FA} \beta+\mathrm{PCA} \beta$ (6.58/113.83). Ferulates and $p$-coumarates, attached primarily to arabinoxylans, are readily observed in grass samples [30,32]. The peak at 7.39/111.03 is assigned to FA2, and FA6 appears at 7.16/123.20 which is overlapping with the solvent peak (pyridine). After the process the signals decreased and FA6 can be only observed with low contour level. The $p$ CA2/6 correlations are well resolved at 7.58/130.09 and $p C A 3 / 5$ position is not resolved from G5 units. FA $\alpha$ and FA $\beta$ correlations coincide with $p C A \alpha$ and $p C A \beta$ respectively at positions $7.67 / 145.08$ and $6.58 / 113.83 \mathrm{pm}$. Integrals from well resolved 2,6-positions of each type of lignin can be used to calculate the H:G:S ratio. The integration results for the two samples are shown in Additional file 1: Figure S4. In general, it was observed that all types of lignin signals have been weakened after the pretreatment and hydrolysis process. The S/G ratio decreased from 0.32 to 0.21 after the processing. The anomeric regions (4-5.5/90-
$105 \mathrm{ppm}$ ) indicate that xylan has been mostly removed with the disappearance of the peaks at 4.60/99.47 and $4.39 / 101.77 \mathrm{ppm}$ which corresponds to xylan acetate $(2-\mathrm{O}-\mathrm{Ac}-\beta-\mathrm{D}-\mathrm{Xyl} p)$ and xylan $[(1 \rightarrow 4)-\alpha-\mathrm{D}-\mathrm{Gl} c p]$. The intensities of the peaks for cellulose reducing ends [Glc (R), 5.08/92.27 \& 4.46/96.98] have been greatly enhanced in the solid residue, indicating a lower degree of polymerization (DP) after the process. These results indicate that the solid residue has experienced significant compositional and chemical changes after the acidolysis and extraction process. Most of the xylan has been removed, whereas lignin and cellulose has been left with modified structures. 2D NMR shows detailed bonding structures, however, the dissolution of the samples in the solvent mixture was not complete, and may not be a representative fraction of the whole solid residue.

The data presented in Table 7 and Additional file 1: Figure S5 show the molecular distribution of lignin in the switchgrass lignin extracted using the enzymatic mild acidolysis lignin (EMAL) as a control, supernatant after acidolysis, as well as the IL phase and $\mathrm{NaOH}$ phase after phase separation. The data have been presented as large molecular weight material $(\mathrm{t}<15.5 \mathrm{~min}$ elution time, corresponding to $46 \mathrm{k}<\mathrm{u}$ by polystyrene calibration) and small molecular weight material $(t>15.5 \mathrm{~min}$ elution time corresponding to $46 \mathrm{k}>\mathrm{u}$ ). It is observed that after pretreatment and acidolysis the largest component present in the EMAL (7-9 min elution time) is no longer present in the supernatant. Moreover, a significant reduction in larger molecular weight material $(<15.5 \mathrm{~min}$ elution time) and an increase in the smaller molecular weight materials $(>15.5 \mathrm{~min}$ ) were observed. This result indicates that lignin has undergone significant depolymerization during this pretreatment/ acidolysis process at the conditions used. The component of large molecular weight material is $70.1 \%$ before pretreatment but is reduced to $46.2 \%$ after acidolysis. 

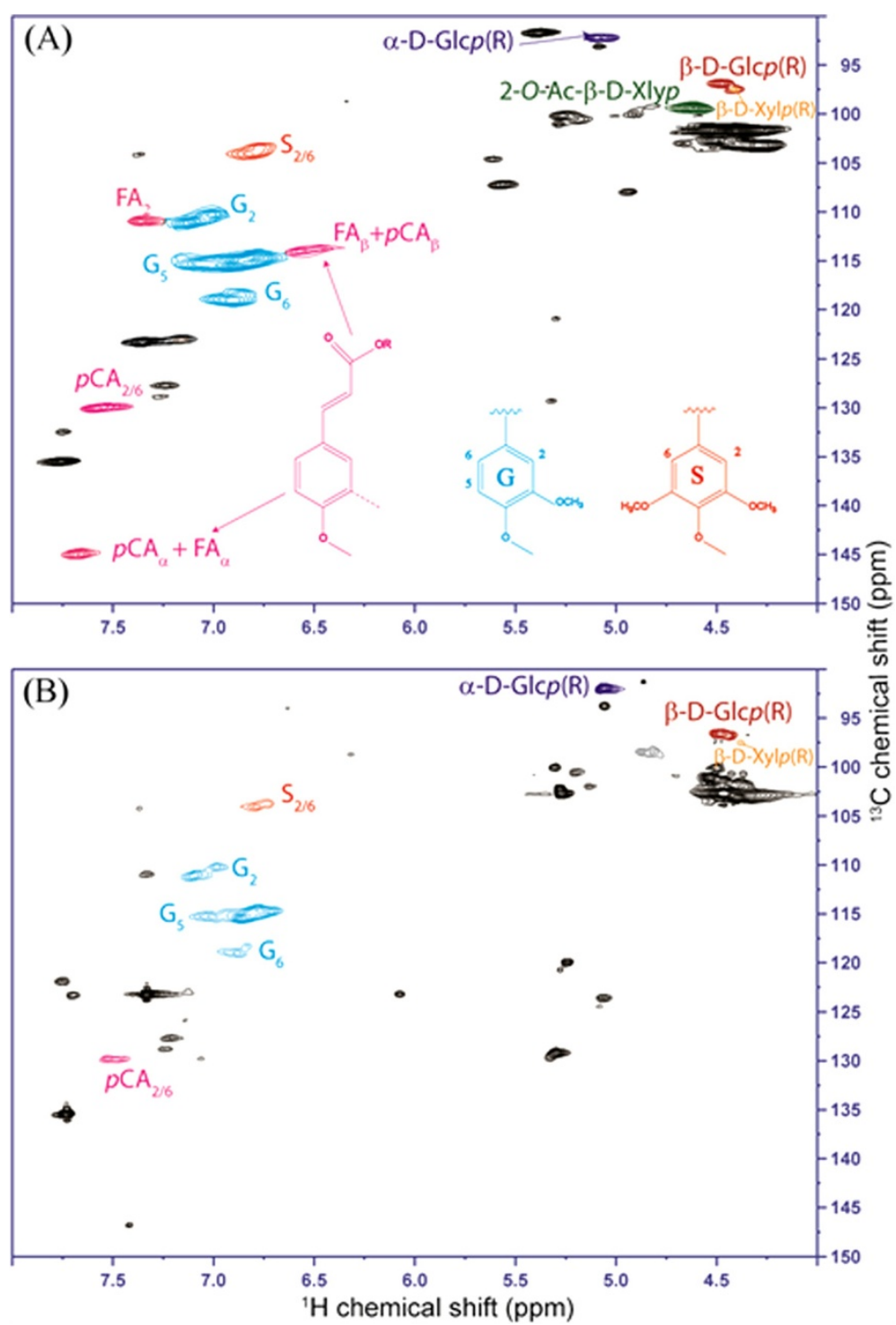

Figure 7 2D 13C-1H correlation (HSQC) spectra from gel samples in DMSO-d6/pyridine-d5 (4:1) for the sampes: original switchgrass (A) and solid residue from run 7 (B).

Furthermore, after phase separation, lignin fractionation is observed between the two phases; only $4.7 \%$ of larger molecular weight material is present in the IL phase, with the remaining larger molecular weight material migrating to the $\mathrm{NaOH}$ phase. The partition of different molecular mass lignin after phase separation gives rise to possible fractionation method for lignin.

\section{Conclusions}

It has been shown that certain concentrations of $\mathrm{NaOH}$ can phase separate with chloride based ILs $\left(\left[\mathrm{C}_{4} \mathrm{mim}\right] \mathrm{Cl}\right.$ and $\left.\left[\mathrm{C}_{2} \mathrm{mim}\right] \mathrm{Cl}\right)$ forming upper phase, IL rich and lower phase, alkaline rich. Both glucose and xylose prefer to partition to the alkaline rich phase. By combining this system with the acidolysis of biomass in IL, sugar monomers can be easily extracted from the aqueous ILs. The sugar yields depend on both the pretreatment conditions and alkali concentrations. Pretreatment under higher temperature results in improved glucose yields but compromises xylose yields. The optimized $\mathrm{NaOH}$ concentration for both phase separation and sugar extraction is $15 \%$. Maximum yields of $54 \%$ glucose and $88 \%$ xylose can be recovered in the alkaline phase with pretreatment condition of $160^{\circ} \mathrm{C}$ for $1.5 \mathrm{~h}$ and $105^{\circ} \mathrm{C}$ for $6 \mathrm{~h}$ respectively followed by acidolysis. Improved sugar yields could be achieved by further optimizing the amount of acid and water used in acidolysis step and the alkali salts used for sugar extraction. Molecular dynamics simulations can be used to predict 
Table 7 Lignin molecular weight distribution (calculated from SEC data in Additional file 1: Figure S5)

\begin{tabular}{lll}
\hline Elution time $(\mathbf{m i n})$ & $\mathbf{t}<\mathbf{1 5}$ & $\mathbf{t}>\mathbf{1 5}$ \\
Molecular mass $(\mathbf{u})^{*}$ & $\mathbf{4 6} \mathbf{k}<\mathbf{u}$ & $\mathbf{4 6} \mathbf{k}>\mathbf{u}$ \\
\hline EMAL & $70.1 \%$ & $29.9 \%$ \\
Before phase separation & $46.2 \%$ & $53.8 \%$ \\
IL phase & $4.7 \%$ & $95.3 \%$ \\
$\mathrm{NaOH}$ phase & $69.8 \%$ & $30.2 \%$ \\
\hline
\end{tabular}

*Based on polystyrene calibration.

sugar partitioning in the system, but the sugar partition coefficients are found to be affected by the presence of biomass.

Consolidated pretreatment and hydrolysis using ILs and acid catalysts offers a promising route to the production of fermentable sugars without the need for enzymes. The use of alkali salts to form ABS to recover the sugars and recycle the IL may provide a scalable and economical process. The advantages of the process are: 1 ) sugars can be released in situ and extracted by alkaline solution with relatively high yields, and without the need for any enzymes; 2) the formation of an aqueous biphasic system enables facile recovery of the sugars and IL recovery at the same time; 3 ) significantly reduced volume of water $(<50 \mathrm{wt} \%$ of total mixture) is used as compared to more traditional IL based pretreatment process. Future research should be focused on recovery of the residual biomass in the IL rich phase, test the IL recycling efficiency, and desalting of the alkaline rich phase to make it compatible with downstream fermentation microbes.

\section{Methods}

\section{Biomass pretreatment and acidolysis of dissolved} biomass

The pretreatment and acidolysis process flow is shown in Additional file 1: Figure S6. Biomass solutions were prepared by combining different amounts $(0.5 \mathrm{~g}, 0.75 \mathrm{~g}$, $1 \mathrm{~g}$, and $1.5 \mathrm{~g}$ ) of switchgrass with $10 \mathrm{~g}\left[\mathrm{C}_{4} \mathrm{mim}\right] \mathrm{Cl}$ in an $80 \mathrm{~mL}$ glass bottle. The mixtures were heated and stirred in an oil bath at different conditions. All experiments were conducted in duplicates. Solutions were then placed into another oil bath which was already equilibrated at the acidolysis temperature of $105^{\circ} \mathrm{C}$ and acidolysis started after 15 min equilibration.

Acidolysis was performed following a procedure described previously [27]. In summary, $4 \mathrm{M} \mathrm{HCl}$ was added to the biomass- $\left[\mathrm{C}_{4} \mathrm{mim}\right] \mathrm{Cl}$ solution $(\mathrm{t}=0)$ at concentrations of $100 \mathrm{mg} \mathrm{HCl}$ per g biomass and with DI water added to give a $\mathrm{H}_{2} \mathrm{O}$ concentration of $5 \%(\mathrm{w} / \mathrm{w})$ of the total weight. More water was added at different time intervals (10 $\mathrm{min}, 20 \mathrm{~min}, 30 \mathrm{~min}$, and $60 \mathrm{~min}$ ) to result in targeted water concentrations of $20,25,33$ and $43 \%$. Continuous water addition using a syringe pump was also attempted to compare the effect on sugar yields. Water was pumped into the mixture starting from either 10 or $15 \mathrm{~min}$ at the rate of 157.2 or $121.1 \mathrm{uL} / \mathrm{min}$ for 50 or $45 \mathrm{~min}$. Acidolysis was continued for a total of $2.5 \mathrm{~h}$ and stopped by taking the bottle out of the oil bath with/without addition of extra amount of water $(0,7.5$, or $15 \mathrm{~mL}$ ). The mixture was transferred into centrifuge tubes and centrifuged at high speed $(10,000 \mathrm{rpm})$ to separate the solid residue from the aqueous solutions. The solid residue was washed with $5 \times 40 \mathrm{~mL}$ of water, and after the final wash the sample was lyophilized for two days for further analysis.

\section{Extraction of sugars using alkaline solution Extraction of sugar standards}

$33 \mathrm{mg}$ glucose and $21 \mathrm{mg}$ xylose were used to simulate the sugar outputs obtained from $0.1 \mathrm{~g}$ biomass. These sugars were dissolved in an $\mathrm{IL}_{-} \mathrm{H}_{2} \mathrm{O}$ mixture $(2 \mathrm{~g} \mathrm{IL}+$ $1.5 \mathrm{~g} \mathrm{H}_{2} \mathrm{O}$ ) in a $15 \mathrm{~mL}$ centrifuge tube. $70 \mu \mathrm{L}$ of $4 \mathrm{M}$ $\mathrm{HCl}$ was added to the mixture and mixed in an incubator at $30^{\circ} \mathrm{C}$ and $1400 \mathrm{rpm}$ for $30 \mathrm{~min} .1 \mathrm{~mL}$ of the mixture solution was placed in to a $2 \mathrm{~mL}$ eppendorf tube and different amounts (ca. 130 or $200 \mathrm{uL}$ ) of concentrated $\mathrm{NaOH}(50 \% \mathrm{w} / \mathrm{w})$ were added to give the final $\mathrm{NaOH}$ concentration either 15 or $20 \mathrm{wt} \%$ (considering the water in the system). The mixture was agitated in a thermomixer at RT and $1400 \mathrm{rpm}$ for $0.5 \mathrm{~h}$ and then centrifuged at high speed $(14,000 \mathrm{rpm})$ to phase separate. The upper IL phase and lower $\mathrm{NaOH}$ phase were separated with a pipette and the sugar content was quantified. The volume of the upper and lower phase was calculated by measuring the mass and density of both phases.

\section{Extraction of acidolysis sugars}

The procedure is similar to the extraction of sugar standard except that only $15 \mathrm{wt} \% \mathrm{NaOH}$ (final concentration, based on the water in the system) was used based on the results from the sugar standards. The total volume of the supernatant was calculated based on the total mass and density of the supernatant after separation of the solid residue.

\section{Analysis and characterization methods}

All aqueous solutions were analyzed for sugars using High Performance Anion Exchange Chromatography with Pulsed Amperometric Detection (HPAEC-PAD) on a Dionex ICS 3000 equipped with a Dionex CarboPac PA-20 analytical column $(3 \times 150 \mathrm{~mm})$, according to procedures described previously $[8,33]$. Elution was initiated with $89 \%$ $(\mathrm{v} / \mathrm{v})$ water and $11 \%(\mathrm{v} / \mathrm{v}) 1 \mathrm{M} \mathrm{NaOH}$ for the first $13.5 \mathrm{~min}$, with $10 \mu \mathrm{L}$ injection volume and $0.4 \mathrm{~mL} / \mathrm{min}$ for the flow rate. A 5 min gradient was applied and elute concentration was then switched to $55 \%(\mathrm{v} / \mathrm{v})$ water and $45 \%$ 
(v/v) $100 \mathrm{mM} \mathrm{NaOH}$ for $30 \mathrm{~min}$. Sugar standards fucose, arabinose, rhamnose, galactose, glucose, xylose, fructose, and cellubiose obtained from Sigma-Aldrich were used as the external standards for HPAEC, and prepared at levels of 6.25 to $100 \mu \mathrm{M}$ before use.

Furfural and HMF was analyzed using an Agilent 1200 High Pressure Liquid Chromatography (HPLC) instrument equipped with Aminex HPX-87 $\mathrm{H}$ column and a UV detector $(\lambda=280 \mathrm{~nm})$. Eluent containing $4 \mathrm{mM}$ $\mathrm{H}_{2} \mathrm{SO}_{4}$ was used and the flow rate was $0.6 \mathrm{~mL} / \mathrm{min}$. Standard calibration curves were made by using 6 different known concentrations of furfural/HMF (125-1000 uM) from Sigma-Aldrich. Ionic liquid was quantified using reversed phase liquid chromatography using an HPLC equipped with Eclipse Plus C8 column and Evaporative Light Scattering Detector (ELSD, evaporator temperature = $45^{\circ} \mathrm{C}$, nebulizer temperature $=30^{\circ} \mathrm{C}$; gas flow $=1.2$ ). All analyses were performed at $0.5 \mathrm{~mL} / \mathrm{min}$ flow rate. The injection volume was $5 \mu \mathrm{L}$ and the column temperature was $30^{\circ} \mathrm{C}$.

The chemical composition of the biomass before and after pretreatment was tracked using an acidolysis protocol that followed the NREL Laboratory Analytical Protocols (LAP) LAP-002 and LAP-005 scaled down to the volumes of the samples [34]. In short, $0.2 \mathrm{~g}$ biomass and $2 \mathrm{~mL} 72 \% \mathrm{H}_{2} \mathrm{SO}_{4}$ was incubated at $30^{\circ} \mathrm{C}$ with shaking rate of $300 \mathrm{rpm}$ for $1 \mathrm{~h}$. The solution was diluted down to $4 \% \mathrm{H}_{2} \mathrm{SO}_{4}$ and autoclaved for $1 \mathrm{~h}$ at $121^{\circ} \mathrm{C}$. The reaction was quenched by placing the samples into an ice bath and then filtered. Carbohydrate concentrations were determined using HPAEC and the acid insoluble lignin was quantified gravimetrically.

XRD data were collected with a PANalytical Empyrean $\mathrm{X}$-ray diffractometer equipped with a PIXcel ${ }^{3 \mathrm{D}}$ detector and operated at $45 \mathrm{kV}$ and $40 \mathrm{kA}$ using $\mathrm{Cu} K \alpha$ radiation $(\lambda=1.5418 \AA)$. The patterns were collected in the $2 \theta$ range of 5 to $55^{\circ}$, the step size was $0.026^{\circ}$, and the exposure time was 300 seconds. A reflection-transmission spinner was used as a sample holder and the spinning rate was set at $8 \mathrm{rpm}$ throughout the experiment. The crystallinity index (CrI) was determined from the crystalline and amorphous peak areas by a curve fitting procedure of the measured diffraction patterns using the software package HighScore Plus ${ }^{\circledR}$ according to Eq. 6:

$$
C r I=\frac{\sum A_{c r .}}{\sum A_{c r .}+\sum A_{a m} .}
$$

NMR samples were ball milled using a Retsch PM 100 planetary ball mill at $600 \mathrm{rpm}$ with a stainless steel grinding jar $(50 \mathrm{~mL})$ containing zirconium dioxide balls $(10 \mathrm{~mm} \times 10)$. The samples were milled for $6 \mathrm{~h}$ with 5 min grinding intervals with 5 min breaks. $25 \mathrm{mg}$ of these milled biomass samples were mixed with $500 \mathrm{uL}$ pre-mixed DMSO- $d 6 /$ pyridine- $d 5(4: 1 \mathrm{v} / \mathrm{v})$ directly in NMR tubes according to the report by Ralph et al [30]. The tubes were placed into an ultrasonic bath with the temperature at $50^{\circ} \mathrm{C}$ and for $8 \mathrm{~h}$ to swell/dissolve the biomass. Heteronuclear single quantum coherence (HSQC) spectra were recorded at $310 \mathrm{~K}$ using a Bruker Avance$600 \mathrm{MHz}$ equipped with a cryo-probe (hsqcetgpsisp.2, ns = $128, \mathrm{ds}=16, \mathrm{~d} 1=0.5 \mathrm{~s}, \mathrm{td}=1 \mathrm{k}$, number of increments = 512). DMSO was used as an internal reference. Topspin was used for processing and analysis of the data.

Size exclusion chromatography (SEC) was employed to assess changes in lignin mass distribution. An EMAL lignin of switchgrass was employed as a control [35]. EMAL has shown to be more representative of the total lignin present in biomass compared to the lignin extracted using other protocols such as milled wood lignin (MWL) or cellulolytic enzyme lignin (CEL) [36,37]. Lignin solutions were prepared in analytical grade $\mathrm{N}$ methyl-2-pyrrolidinone (NMP) and dimethylsulfoxide (DMSO) $(1: 1, \mathrm{v} / \mathrm{v})$ with sonication for 3 hours at $40^{\circ} \mathrm{C}$. Polydispersity of dissolved lignin was determined using analytical techniques SEC UV-A as previously described [38]. An Agilent 1200 series binary LC system (G1312B) equipped with a DAD (G1315D) was used. Separation was achieved with a Mixed-D column (5 $\mathrm{mm}$ particle size, $300 \mathrm{~mm} \times 7.5 \mathrm{~mm}$ i.d., linear molecular weight range of 200 to $400,000 \mathrm{u}$, Polymer Laboratories) at $80^{\circ} \mathrm{C}$ using a mobile phase of NMP at a flow rate of $0.5 \mathrm{ml} \mathrm{min}^{-1}$. Absorbance of material eluting from the column was detected at $\lambda=300 \mathrm{~nm}$ (UV-A). Molecular mass estimates were determined after calibration of the system with polystyrene standards.

\section{Molecular dynamics simulation of glucose in IL-water- $\mathrm{NaOH}$ system}

Data from molecular dynamics (MD) simulations were used to calculate the partition coefficients of the glucose in the water-IL-sugar- $\mathrm{NaOH}$ system to explain the partitioning of glucose to the upper (IL rich) phase and the lower $(\mathrm{NaOH}$ rich) phase. Four systems (Table 8) were constructed using PACKMOL [39]. To simplify the systems for MD in order to obtain a realistic approximation of the interactions of glucose with each phase, we designed the MD simulation systems to match the concentration of

Table 8 The component of simulated systems

\begin{tabular}{lcccc}
\hline & $\begin{array}{c}\text { Number } \\
\text { of } \mathbf{N a O H}\end{array}$ & $\begin{array}{c}\text { Number } \\
\text { of water }\end{array}$ & $\begin{array}{c}\text { Number of } \\
{\left[\mathbf{C}_{\mathbf{2}} \text { mim }\right] \mathbf{C l}}\end{array}$ & $\begin{array}{c}\text { Number of } \\
\text { glucose }\end{array}$ \\
\hline NaOH phase with sugar & 90 & 300 & 0 & 8 \\
$\mathrm{NaOH}$ phase & 90 & 300 & 0 & 0 \\
IL Phase with sugar & 0 & 200 & 32 & 8 \\
IL phase & 0 & 200 & 32 & 0 \\
\hline
\end{tabular}


each component (either $\left[\mathrm{C}_{2}\right.$ mim $] \mathrm{Cl}$ in IL phase or $\mathrm{NaOH}$ in basic phase) to correspond to the experimental data. The appropriate amount of glucose was added to both the upper and lower phases, and MD simulations were carried out in each of the two phases. Two reference systems of the two phases without glucose were also studied using MD simulations. MD simulations were implemented in AMBER [40], using an all-atom force field based on the generalized AMBER force field (GAFF) [41] for $\left[\mathrm{C}_{2} \mathrm{mim}\right]$ cation [42], the standard $\mathrm{Cl}^{-}$anion force field for chloride ions, and the carbohydrate force field, GLYCAM [43], for glucose. The cutoff radius of non-bonded interactions was set to $8 \AA$. The Particle Mesh Ewald summation method [44] was used to calculate the electrostatic potential with periodic boundary conditions. The initial configurations were energy minimized using the steepest descent algorithm for 1000 steps to remove any unexpected coordinate collisions. The systems were then heated for 200 ps in the NVT ensemble, during which the temperature was increased gradually to the target temperature $(300 \mathrm{~K})$, followed by a further 500 ps of equilibration dynamics in the NPT ensemble using a Nose-Hoover constant pressure $(\mathrm{P}=1$ bar) control algorithm. Finally, 10 ns production runs were carried out in the NPT ensemble. The time step for production runs was 2 fs and the SHAKE algorithm was employed to constrain bonds and angles involving hydrogen atoms. The last $8 \mathrm{~ns}$ of each trajectory were used for analysis. The simulation box sizes, types of molecule and their numbers, and related parameters for the various systems are given in Table 8.

\section{Additional file}

Additional file 1: Table S1. Compositions of the major components in the solid residue. Figure $\mathbf{S 1}$ Chromatograms of the upper IL-rich phase (red, $5 \times$ dilution) and lower salt-rich phase (blue, $3000 \times$ dilution) for standard sugars. Figure $\mathbf{S 2}$ The addition of water at different time intervals. More water is needed at $10 \mathrm{~min}$ to achieve high sugar yields. Figure S3a ${ }^{13} \mathrm{C}$ NMR of the original IL, upper (IL rich) phase, and lower (salt rich rich) phase. Figure S3b ${ }^{1} H$ NMR of the original IL, upper (IL rich) phase, and lower (salt rich) phase. Figure $\mathbf{S 4}$ Lignin integration results based on 2D NMR spectra. Blue: raw switchgrass, Red: solid residue after processing. Figure S5 SEC chromatogram of EMAL lignin from switchgrass (green), supernatant after acidolysis (blue) and IL phase (red). Figure $\mathbf{S 6}$ Process of biomass pretreatment, acid hydrolysis and sugar extraction using alkaline solutions.

\section{Competing interests}

The authors declare that they have no competing interests.

\section{Authors' contribution}

NS carried out the biomass pretreatment, acidolysis, sugar extraction and sugar analysis work, performed the NMR analysis, and drafted the manuscript. $\mathrm{HL}$ and KLS carried out the MD simulation for the system and drafted the simulation related parts of the manuscript. NS and AG performed the SEC analysis of the lignin and drafted the SEC related parts of the manuscript. VS performed the PXRD analysis and drafted the PXRD related parts of the manuscript. MS and $A B$ participated the compositional analysis. $\mathrm{KT}$ contributed to development of phase separation process. BMH contributed to the IL content measurement. SS, BAS and BMH contributed to the original experimental design and general guidance of the paper. All authors suggested modifications to the draft and approved the final manuscript.

\section{Acknowledgements}

The authors thank Prof. Harvey W. Blanch for his thoughtful and valuable comments and review of this manuscript. This research used resources of the National Energy Research Scientific Computing Center, which is supported by the Office of Science of the U.S. Department of Energy under Contract No. DE-AC02-05CH1 1231. The work conducted by the Joint BioEnergy Institute was supported by the Office of Science, Office of Biological and Environmental Research, of the U.S. Department of Energy under Contract No. DE-AC02-05CH11231.

\section{Author details}

${ }^{1}$ Deconstruction Division, Joint BioEnergy Institute, Lawrence Berkeley National Laboratory, Berkeley, CA, USA. ${ }^{2}$ Biological and Materials Sciences Center, Sandia National Laboratories, Livermore, CA, USA. ${ }^{3}$ Hydrogen and Combustion Technologies Department, Sandia National Laboratories, Livermore, CA, USA.

Received: 2 November 2012 Accepted: 8 March 2013 Published: 20 March 2013

\section{References}

1. Claassen P, Van Lier J, Lopez Contreras A, Van Niel E, Sijtsma L, Stams A, De Vries $S$, Weusthuis R: Utilisation of biomass for the supply of energy carriers. Appl Microbiol and Biot 1999, 52:741-755.

2. Top Value Added Chemicals from Biomass Volume 1-Results of Screening for Potential Candidates from Sugars and Synthesis Gas: [http://www1.eere. energy.gov/biomass/pdfs/35523.pdf].

3. Huber GW, Iborra S, Corma A: Synthesis of transportation fuels from biomass: chemistry, catalysts, and engineering. Chem Rev 2006, 106:4044-4098.

4. Zhu S, Wu Y, Chen Q, Yu Z, Wang C, Jin S, Ding Y, Wu G: Dissolution of cellulose with ionic liquids and its application: a mini-review. Green Chem 2006, 8:325-327.

5. Sun N, Rodríguez H, Rahman M, Rogers RD: Where are ionic liquid strategies most suited in the pursuit of chemicals and energy from lignocellulosic biomass? Chem Commun 2010, 47:1405-1421.

6. Mora Pale M, Meli L, Doherty TV, Linhardt RJ, Dordick JS: Room temperature ionic liquids as emerging solvents for the pretreatment of lignocellulosic biomass. Biotechnol Bioeng 2011, 108:1229-1245.

7. Li B, Asikkala J, Filpponen I, Argyropoulos D: Factors affecting wood dissolution and regeneration of ionic liquids. Ind Eng Chem Res 2010 49:2477-2484.

8. Li C, Knierim B, Manisseri C, Arora R, Scheller HV, Auer M, Vogel KP, Simmons BA, Singh S: Comparison of dilute acid and ionic liquid pretreatment of switchgrass: biomass recalcitrance, delignification and enzymatic saccharification. Bioresour Technol 2010, 101:4900-4906.

9. Brandt A, Hallett JP, Leak DJ, Murphy RJ, Welton T: The effect of the ionic liquid anion in the pretreatment of pine wood chips. Green Chem 2010, 12:672-679.

10. Dibble DC, Li C, Sun L, George A, Cheng A, Çetinkol ÖP, Benke P, Holmes BM, Singh S, Simmons BA: A facile method for the recovery of ionic liquid and lignin from biomass pretreatment. Green Chem 2011, 13:3255-3264.

11. Klein-Marcuschamer D, Simmons BA, Blanch HW: Techno-economic analysis of a lignocellulosic ethanol biorefinery with ionic liquid pretreatment. Biofuel Bioprod Bior 2011, 5:562-569.

12. Li C, Wang Q, Zhao ZK: Acid in ionic liquid: an efficient system for hydrolysis of lignocellulose. Green Chem 2008, 10:177-182.

13. Rinaldi R, Palkovits R, Schüth F: Depolymerization of cellulose using solid catalysts in ionic liquids13. Angew Chem Int Edit 2008, 47:8047-8050.

14. Vanoye L, Fanselow M, Holbrey JD, Atkins MP, Seddon KR: Kinetic mode for the hydrolysis of lignocellulosic biomass in the ionic liquid, 1-ethyl-3methyl-imidazolium chloride. Green Chem 2009, 11:390-396.

15. Sievers C, Valenzuela-Olarte MB, Marzialetti T, Musin D, Agrawal PK, Jones CW: Ionic-liquid-phase hydrolysis of pine wood. Ind Eng Chem Res 2009, 48:1277-1286 
16. Amarasekara AS, Owereh OS: Hydrolysis and decomposition of cellulose in Bronsted acidic ionic liquids under mild conditions. Ind Eng Chem Res 2009, 48:10152-10155.

17. Klein-Marcuschamer D, Oleskowicz-Popiel P, Simmons BA, Blanch HW: The challenge of enzyme cost in the production of lignocellulosic biofuels. Biotechnol Bioeng 2012, 109:1083-1087.

18. Gutowski KE, Grant A, Willauer HD, Huddleston JG, Swatloski RP, Holbrey JD, Rogers RD: Controlling the aqueous miscibility of ionic liquids: aqueous biphasic systems of water-miscible ionic liquids and water-structuring salts for recycle, metathesis, and separations. J Am Chem Soc 2003, 125:6632-6633.

19. He C, Li S, Liu H, Li K, Liu F: Extraction of testosterone and epitestosterone in human urine using aqueous two-phase systems of ionic liquid and salt. J Chromatogr A 2005, 1082:143-149.

20. Bridges NJ, Gutowski KE, Rogers RD: Investigation of aqueous biphasic systems formed from solutions of chaotropic salts with kosmotropic salts (salt-salt ABS). Green Chem 2006, 9:177-183.

21. Wu B, Zhang $Y$, Wang $H$ : Phase behavior for ternary systems composed of ionic liquid + saccharides + water. J Phy Chem B 2008, 112:6426-6429.

22. Neves CMSS, Ventura SPM, Freire MG, Marrucho IM, Coutinho JAP: Evaluation of cation influence on the formation and extraction capability of ionic-liquid-based aqueous biphasic systems. J Phys Chem B 2009, 113:5194.

23. Li Z, Pei Y, Wang H, Fan J, Wang J: lonic liquid-based aqueous two-phase systems and their applications in green separation processes. Trend Anal Chem 2010, 29:1336-1346.

24. Li S, He C, Liu H, Li K, Liu F: Ionic liquid-based aqueous two-phase system, a sample pretreatment procedure prior to high-performance liquid chromatography of opium alkaloids. J Chromatogr B 2005, 826:58-62.

25. Li W, Sun N, Stoner B, Jiang X, Lu X, Rogers RD: Rapid dissolution of lignocellulosic biomass in ionic liquids using temperatures above the glass transition of lignin. Green Chem 2011, 13:2038-2047.

26. Arora R, Manisseri C, Li C, Ong MD, Scheller HV, Vogel K, Simmons BA, Singh $S$ : Monitoring and analyzing process streams towards understanding ionic liquid pretreatment of switchgrass (Panicum virgatum L.). Bioenerg Res 2010, 3:134-145.

27. Binder JB, Raines RT: Fermentable sugars by chemical hydrolysis of biomass. PNAS 2010, 107:4516-4521.

28. Li C, Sun L, Simmons BA, Singh S: Comparing the Recalcitrance of Eucalyptus, Pine, and Switchgrass Using lonic Liquid and Dilute Acid Pretreatments. BioEnergy Research 2013, 6:14-23.

29. Binder JB, Raines RT: Simple chemical transformation of lignocellulosic biomass into furans for fuels and chemicals. JACS 2009, 131:1979-1985.

30. Kim H, Ralph J: Solution-state 2D NMR of ball-milled plant cell wall gels in DMSO-d6/pyridine-d5. Org Biomol Chem 2010, 8:576-591.

31. Samuel R, Pu Y, Raman B, Ragauskas A: Structural characterization and comparison of switchgrass ball-milled lignin before and after dilute acid pretreatment. Appl Biochem Biotechnol 2010, 162:62-74.

32. Lam TBT, Kadoya K, liyama K: Bonding of hydroxycinnamic acids to lignin: ferulic and p-coumaric acids are predominantly linked at the benzyl position of lignin, not the $\beta$-position, in grass cell walls. Phytochemistry 2001, 57:987-992

33. Brennan TCR, Datta S, Blanch HW, Simmons BA, Holmes BM: Recovery of sugars from ionic liquid biomass liquor by solvent extraction. Bioenerg Res 2010, 3:123-133.

34. Sluiter A, Hames B, Ruiz R, Scarlata C, Sluiter J, Templeton D: Determination of structural carbohydrates and lignin in biomass. LAP-002 NREL Analytical Procedure. 2004. National Renewable Energy Laboratory Golden, CO.

35. Wu S, Argyropoulos D: An improved method for isolating lignin in high yield and purity. J Pulp Pap Sci 2003, 29:235-240.

36. Guerra A, Filpponen I, Lucia LA, Argyropoulos DS: Comparative evaluation of three lignin isolation protocols for various wood species. J Agric Food Chem 2006, 54:9696-9705.

37. Guerra A, Filpponen I, Lucia LA, Saquing C, Baumberger S, Argyropoulos DS: Toward a better understanding of the lignin isolation process from wood. J Agric Food Chem 2006, 54:5939-5947.

38. George A, Tran K, Morgan T, Benke P, Berrueco C, Lorente E, Wu B, Keasling J, Simmons BA, Holmes B: The effect of ionic liquid cation and anion combinations on the macromolecular structure of lignins. Green Chem 2011, 13:3375-3385.
39. Martínez L, Andrade R, Birgin E, Martínez J: Packmol: a package for building initial configurations for molecular dynamics simulations. J Comput Chem 2009, 30:2157-2164.

40. Case DA, Darden TA, Cheatham TE III, Simmerling CL, Wang J, Duke RE, Luo R, Crowley M, Walker RC, Zhang W, Merz KM, Wang B, Hayik S, Roitberg A, Seabra G, Kolossváry I, Wong KF, Paesani F, Vanicek J, Wu X, Brozell SR, Steinbrecher T, Gohlke H, Yang L, Tan C, Mongan J, Hornak V, Cui G, Mathews DH, Seetin MG, Sagui C, Babin V, Kollman PA: AMBER 10. San Francisco: University of California; 2008.

41. Wang J, Wang W, Kollman PA, Case DA: Automatic atom type and bond type perception in molecular mechanical calculations. J Mol Graph Model 2006, 25:247-260.

42. Liu H, Sale KL, Holmes BM, Simmons BA, Singh S: Understanding the interactions of cellulose with ionic liquids: a molecular dynamics study. J Phys Chem B 2010, 114:4293-4301.

43. Woods RJ, Dwek RA, Edge CJ, Fraser-Reid B: Molecular mechanical and molecular dynamic simulations of glycoproteins and oligosaccharides. 1. GLYCAM_93 parameter development. J Phys Chem 1995, 99:3832-3846.

44. Darden T, York D, Pedersen L: Particle mesh Ewald: an N log (N) method for Ewald sums in large systems. J Chem Phys 1993, 98:10089.

\section{doi:10.1186/1754-6834-6-39}

Cite this article as: Sun et al:: Production and extraction of sugars from switchgrass hydrolyzed in ionic liquids. Biotechnology for Biofuels 2013 6:39.

\section{Submit your next manuscript to BioMed Central and take full advantage of:}

- Convenient online submission

- Thorough peer review

- No space constraints or color figure charges

- Immediate publication on acceptance

- Inclusion in PubMed, CAS, Scopus and Google Scholar

- Research which is freely available for redistribution

Submit your manuscript at www.biomedcentral.com/submit
C) Biomed Central 